\title{
Evaluation of the efficacy and safety of vilazodone for treating major depressive disorder
}

\author{
This article was published in the following Dove Press journal: \\ Neuropsychiatric Disease and Treatment \\ 4 August 2015 \\ Number of times this article has been viewed
}

\section{Xiao-Fei Zhang \\ Lei $\mathrm{Wu}$ \\ Dong-Jun Wan \\ Ruo-Zhuo Liu \\ Zhao Dong \\ Min Chen \\ Sheng-Yuan Yu}

Department of Neurology, Chinese

PLA General Hospital, Beijing,

People's Republic of China
Correspondence: Sheng-Yuan Yu Department of Neurology, Chinese PLA General Hospital, 28 Fuxing Road, Haidan District, Beijing 100853, People's Republic of China

$\mathrm{Tel} / \mathrm{fax}+861068182255$

Email yusy1963@I26.com
Purpose: Vilazodone is a novel serotonin (5-HT)-reuptake inhibitor and 5-HT ${ }_{1 \mathrm{~A}}$ partial agonist that was recently developed for the treatment of major depressive disorder (MDD). We conducted a meta-analysis and systematic review to better evaluate the efficacy and safety of vilazodone.

Materials and methods: We performed a thorough literature search to identify all randomized double-blind placebo-controlled trials that were designed to investigate the efficacy of vilazodone for the treatment of MDD, and that were published in electronic databases, including Medline, Embase, and the Cochrane Central Register of Controlled Trials. A manual search was also conducted to investigate the relevant references of the retrieved studies. Subsequently, we conducted a meta-analysis and systematic literature review.

Results: A total of five randomized controlled trials were finally included, involving 1,200 patients with vilazodone and 1,193 patients with placebo. The primary efficacy end point of the Montgomery-Åsberg Depression Rating Scale (standardized mean difference $-3.58,95 \%$ confidence interval -4.59 to $-2.56 ; P<0.00001)$, and the key secondary efficacy end points (Clinical Global Impression - Severity scale, Clinical Global Impression - Improvement scale, and Hamilton Anxiety Rating Scale) indicated that vilazodone was more effective than placebo. Most common adverse events, including diarrhea and nausea, were evaluated, and safety assessments indicated that vilazodone was well tolerated (diarrhea odds ratio 3.54, 95\% confidence interval 2.81-4.45; $P<0.00001$; nausea odds ratio $3.85,95 \%$ confidence interval $3.00-4.96$; $P<0.00001$; discontinuations due to adverse events odds ratio $2.71,95 \%$ confidence interval $1.81-4.05 ; P<0.00001)$.

Conclusion: Our findings indicate that the novel antidepressant vilazodone is effective and safe for MDD, with a low occurrence of side effects. It offers promise as an effective oral drug for the treatment of MDD, with a balance of efficacy and tolerability.

Keywords: vilazodone, major depression, systematic review, antidepressant, randomized controlled trial

\section{Introduction}

Major depressive disorder (MDD) is a serious chronic and recurrent psychiatric illness, and accounts for $10 \%-14 \%$ of all patients seen by primary care physicians. ${ }^{1-3}$ It is the third major cause of moderate-to-severe disability and worldwide burden of disease. ${ }^{4,5}$ The cardinal symptoms of MDD include diminished pleasure or interest in daily activities, changes in appetite or weight, sleep disorders, difficulty concentrating, fatigue, psychomotor agitation, sad mood, feelings of worthlessness, and even suicidal thoughts. ${ }^{6}$ Despite the current availability of different types of antidepressants, many patients with depression do not achieve adequate remission after treatment. Selective serotonin (5-HT)-reuptake inhibitors (SSRIs) are relatively effective treatments for MDD and the most commonly prescribed first-line treatment options. Many patients 
may show strong response to or tolerate a different $\mathrm{SSRI}^{7}$ if they do not adequately respond to or do not tolerate their initial SSRI. ${ }^{8}$ Although all SSRIs modulate serotonin reuptake, they differ in their pharmacologic profiles, which may influence efficacy and tolerability in individual patients. It is necessary to explore novel medications with superior clinical efficacy and good tolerability for patients with MDD.

Vilazodone is a new antidepressant with a unique mechanism of action whereby it simultaneously acts as an SSRI and a 5-HT ${ }_{1 \mathrm{~A}}$-receptor partial agonist. ${ }^{9-12}$ It was approved in 2011 by the US Food and Drug Administration for the treatment of MDD in adults. ${ }^{13}$ Clinicians have speculated that because vilazodone combines serotonin-reuptake inhibition and has a buspirone-like anxiolytic mechanism, it could be an effective and well-tolerated class of drug for patients with MDD symptoms. ${ }^{14,15}$

The purpose of the present study was to review the currently available clinical studies referring to vilazodone and to summarize all the data to objectively evaluate the efficacy of this antidepressant for the treatment of MDD by meta-analysis.

\section{Materials and methods \\ Data sources and search strategy}

All randomized controlled trials (RCTs) reporting the effect of vilazodone for treating MDD were systematically searched in the Medline, Embase, and Cochrane Central Register of Controlled Trials databases until April 2015. In our search strategy, the following keywords were used: "vilazodone", "major depressive disorder", and "randomized controlled trial". In addition, a manual search was conducted to investigate the relevant references of the retrieved publications.

\section{Inclusion criteria}

All the selected articles were screened according to the following criteria for inclusion: 1) articles referring to treatment with vilazodone for patients with MDD, 2) detailed data including the values of each index and the total number of each group available to be analyzed, 3) published as a full text up to April 2015. If the same author reported various articles sharing the identical case series, only the study with the most patients was used, and if the same research was published in different journals, only the most recent article was included for analysis. The flowchart depicting the studyselection process is presented in Figure 1.

\section{Quality assessment}

We assessed the methodological quality of each trial using the Jadad scale ${ }^{16}$ according to the following aspects: how the participants were allocated to the group of the studies, whether the articles stated explicitly the method of blinding, and whether they described the missing data due to attrition and explained the reason for dropouts. Based on the guidelines published in the Cochrane Handbook for Systematic Reviews of Interventions, ${ }^{17}$ each trial was then classified qualitatively and assigned to one of the three following rates: A, if the study met all quality criteria adequately and a low risk of bias was thought to exist; B,

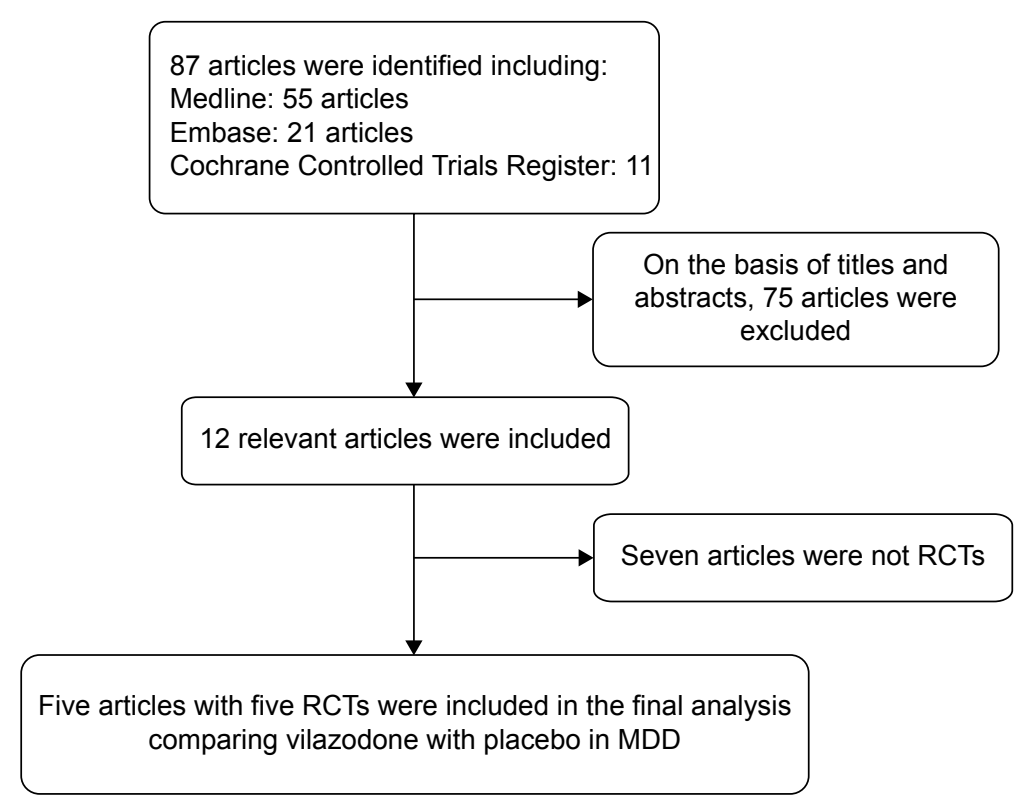

Figure I Flow diagram of the study-selection process.

Abbreviations: RCTs, randomized controlled trials; MDD, major depressive disorder. 
if the study partially met one or more of the quality criteria or the criteria were unclear and a moderate risk of bias was thought to exist; and $\mathrm{C}$, if the study did not meet or include one or more of the criteria and a high risk of bias was thought to exist.

\section{Data extraction}

Usable information was collected from each paper: 1) first author's name, 2) sample size, 3) country of the study, 4) year of publication, 5) therapy that the persons were treated with, and 6) data including the Montgomery-Åsberg Depression Rating Scale (MADRS), Clinical Global Impression Severity scale (CGI-S), CGI - Improvement scale (CGI-I), Hamilton Anxiety Rating Scale (HAMA), diarrhea, nausea, and discontinuations due to an adverse event (AE).

\section{Statistical analysis}

Relevant data included in the meta-analysis were compared by using RevMan version 5.1.0. ${ }^{17}$ Differences between entry and completion of study were evaluated according to changes in MADRS, CGI-S, CGI-I, HAMA, diarrhea, nausea, and discontinuations due to an AE. We used the fixed-effect model (Mantel-Haenszel method) and randomeffect model (DerSimonian-Laird method) to evaluate the standardized mean difference for continuous data and the relative risk for dichotomous results pooled across studies with a corresponding 95\% confidence interval (CI). ${ }^{18}$ The study was considered to be homogeneous only when the analysis showed $P>0.05$, and then the fixed-effect model was chosen for meta-analysis; otherwise, the random-effect model was considered more appropriate. Inconsistency across studies was quantified by the $I^{2}$ statistic, which describes the true extent of heterogeneity but not as a result of chance in results. ${ }^{19} I^{2}$ values ranged from $0 \%$ to $100 \%$, representing a low level of heterogeneity if $I^{2}<25 \%$ and significant inconsistency if $I^{2}>50 \%$.

\section{Results}

\section{Characteristics of included studies}

Initially, a total of 87 articles that may have offered usable data for our meta-analysis were included by the electronic and manual searches. We removed 75 studies after reviewing the titles and abstracts of the included articles according to the predefined inclusion and exclusion criteria. Among the remaining 12 articles, seven articles were excluded as not RCTs, and thus five RCTs ${ }^{20-24}$ that compared vilazodone with placebo were considered eligible for the analysis (Figure 1). The relevant information about the five included articles is listed in Table 1.

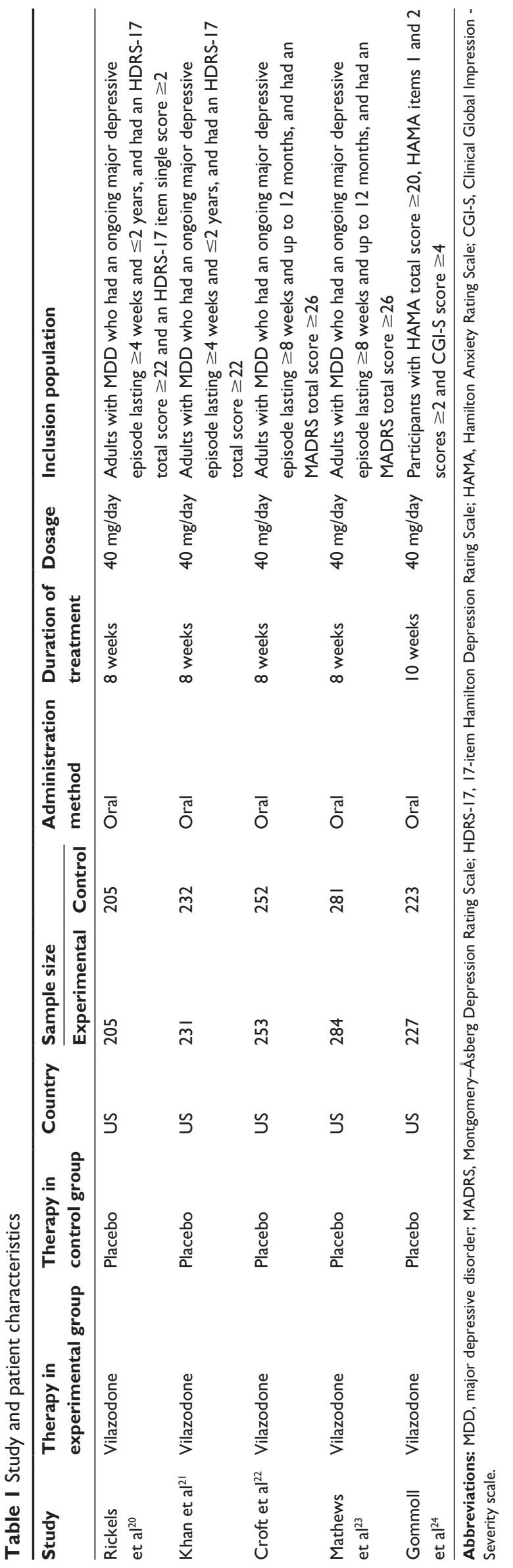

Neuropsychiatric Disease and Treatment 20I5:I I

submit your manuscript 


\section{Quality of each study}

All of the studies included were double-blinded RCTs. Each described how to run the randomization processes and confirmed the optimal sample size by power-calculation methodologies (Table 2). The quality level of each study was A (Table 2). A funnel plot was performed through software to analyze whether the studies had statistical evidence of publication bias. It reflected the relationship between treatment effect and sample size for each included study. From the funnel plot, no significant publication bias was found (Figure 2).

\section{Efficacy}

To evaluate the efficacy of vilazodone for patients with MDD, we analyzed the data referring to MADRS, CGI-S, CGI-I, and HAMA. As for MADRS, only four of the five studies were included, representing 1,943 patients (973 in the vilazodone group and 970 for placebo), and the remaining indices were all studied in the five articles, which included 2,393 patients (1,200 in the vilazodone group and 1,193 in the placebo group) (Figure 3). After the analysis, we got similar results for the indexes (MADRS, CGI-S, CGI-I, and HAMA): no significant heterogeneity was detected across studies ( $P>0.05$ for all), and the fixed-effect model was then performed. As shown in Figure 3, the pooled estimates for standardized mean difference were $-3.58,-0.33,-0.54$, and -1.64 ( $95 \% \mathrm{CI}-4.59$ to $-2.56,-0.41$ to $-0.25,-0.62$ to -0.46 , and -2.07 to -1.22 , respectively; $P<0.00001$ for all). Based on the meta-analysis, it was proven that compared with placebo, vilazodone showed dramatically greater reductions in MADRS, CGI-S, CGI-I, and HAMA scores.

\section{Safety}

As for the common AEs with vilazodone, diarrhea, nausea, and discontinuation due to $\mathrm{AE}$ data were evaluated in the five studies, including 2,393 participants (1,200 in the vilazodone group and 1,193 in the placebo group) (Figure 4). In the subsequent analysis, effect size was expressed as odds ratios (ORs). Compared with the control group, five RCTs showed diarrhea data (OR 3.54, 95\% CI 2.84-4.45; $P<0.00001$ ), nausea data (OR 3.85, 95\% CI 3.00-4.96; $P<0.00001$ ), and discontinuation due to AE data (OR 2.71, 95\% CI 1.81-4.05; $P<0.00001$ ) (Figure 4). These results suggested that the incidences of diarrhea and nausea in the vilazodone group were higher than in the placebo group, and discontinuation due to AEs was significantly less likely to occur with the placebo.

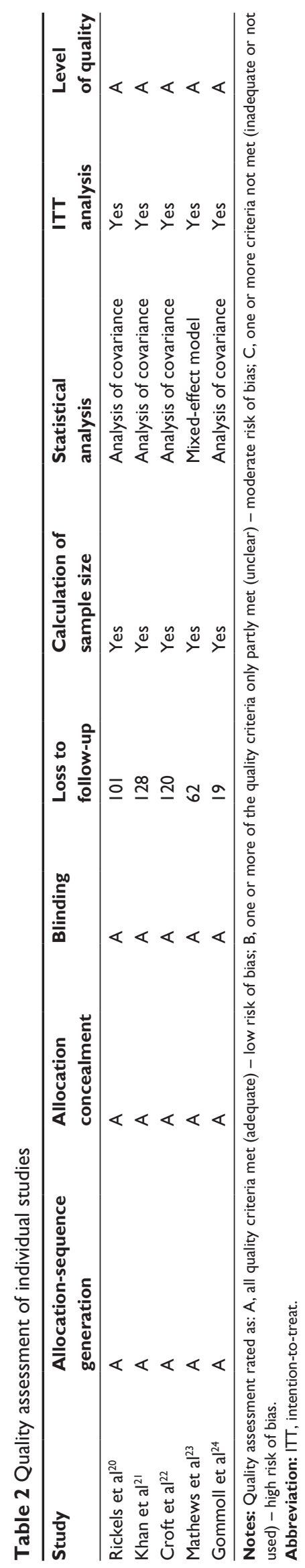




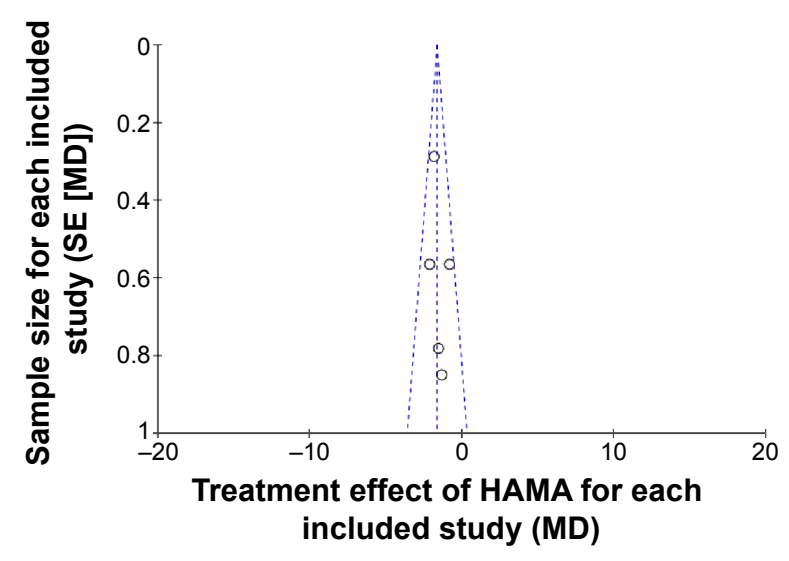

Figure 2 Funnel-plot analysis to detect publication bias.

Notes: Each circle represents the indicated association between treatment effect and sample size for an individual study.

Abbreviations: MD, mean difference; SE, standard error.

\section{Discussion}

Depression is the most common psychiatric disorder and a leading cause of disability worldwide. ${ }^{25,26}$ It is reported that an estimated 8 million individuals meet criteria for MDD, and about $10 \%$ of the adult population experiences a major depressive episode each year in the US. ${ }^{27,28}$ Changes in cognitive-emotional and physical symptoms of depression translate to extensive impairments in psychosocial functioning across physical, occupational, and social domains that severely affect the patient's quality of life. ${ }^{29,30}$ The likelihood of long-term treatment success is improved with early, quick, and accurate diagnosis, multidimensional assessment, and rational pharmacotherapy tailored to each patient's symptomatology, coexisting disorders, and treatment needs. ${ }^{31}$ The first-generation antidepressants are classified as monoamine oxidase inhibitors (MAOIs) and tricyclic antidepressants (TCAs). ${ }^{32}$ The side-effect profile of these two drug classes is one of the major factors that limit their use. Compared with MAOIs and TCAs, in general SSRIs have been found to show similar efficacy in the treatment of depressed outpatients, with a better tolerability profile. ${ }^{33}$ As a result, TCAs and MAOIs were rapidly supplanted by SSRIs as the first choice for both psychiatrists and primary care providers for treating depression. ${ }^{34}$

Vilazodone, which is the first of a new class of antidepressants called indolealkylamines, has been approved for the treatment of MDD and has dual-acting properties combining SSRI and 5-HT $1 \mathrm{~A}$ partial agonist activity. ${ }^{13}$ On the basis of its unique action mechanism for patients with depression, vilazodone offers the potential advantage of faster treatment effect with lower AE risks characterized by good tolerability compared with currently used antidepressants.
Several articles reviewing the currently available studies about vilazodone showed that it was an effective and safe treatment option with its novel action mechanisms for patients with depression. ${ }^{35-37}$ We further evaluated similar aims through a meta-analysis, which was thought to be a reliable and objective approach. To our knowledge, this is the first study to conduct a thorough meta-analysis studying the efficacy and safety of vilazodone for treating MDD. Based on the meta-analysis, vilazodone at $40 \mathrm{mg}$ per day proved to be superior to placebo in improving MADRS, CGI-S, CGI-I, and HAMA scores. Our study shows that treatment with vilazodone can offer both statistically significant and more importantly clinically satisfactory improvements for patients with MDD. Three of the RCTs evaluating the 17-item Hamilton Depression Rating Scale (HDRS-17) also showed that vilazodone was superior to placebo in improving the symptoms of MDD. ${ }^{20,21,24}$ Among these, Rickels et $\mathrm{al}^{20}$ analyzed the changes from baseline to end point in HDRS-17 total score, which was significantly greater with vilazodone than with placebo $(-10.4 \pm 0.6$ versus $-8.6 \pm 0.6, P=0.022)$. Khan et $\mathrm{al}^{21}$ reported the HDRS-17 response (defined as $\geq 50 \%$ decrease from baseline) was also significantly higher with treatment than placebo over 8 weeks $(44.2 \%$ versus $32.9 \%, P=0.013$ ). Recently, similar results on the same index were reported, although they did not reach statistical significance $(-5.56$ versus $-4.67, P=0.0863) .{ }^{24}$ In addition, Robinson et $\mathrm{al}^{38}$ demonstrated that $40 \mathrm{mg}$ per day for 1 year was also safe and well tolerated by adults with MDD.

The unique dual mechanism of action for vilazodone can shorten the onset of antidepressant activity along with enhanced remission and response rates, which may explain the satisfactory clinical efficacy and decreased side effects attributed to serotonin-reuptake inhibition, and provide enhanced benefits for symptoms of anxiety. ${ }^{14,15,21}$

Side effects, such as diarrhea, nausea, and discontinuations due to AEs, induced by vilazodone were higher than placebo. Gastrointestinal AE incidence in the current study was consistent with observations from vilazodone-registration studies. Similarly to prior studies, most instances of vilazodone-related diarrhea and nausea were mild or moderate in intensity, led to few premature discontinuations, occurred within the first few weeks of treatment, and were transient in nature. Overall, treatment with vilazodone was well tolerated. Furthermore, the incidence of markedly abnormal laboratory or vital sign changes was low and similar between the treatment groups.

The meta-analysis included only studies with all data derived from randomized, double-blind, placebo-controlled 


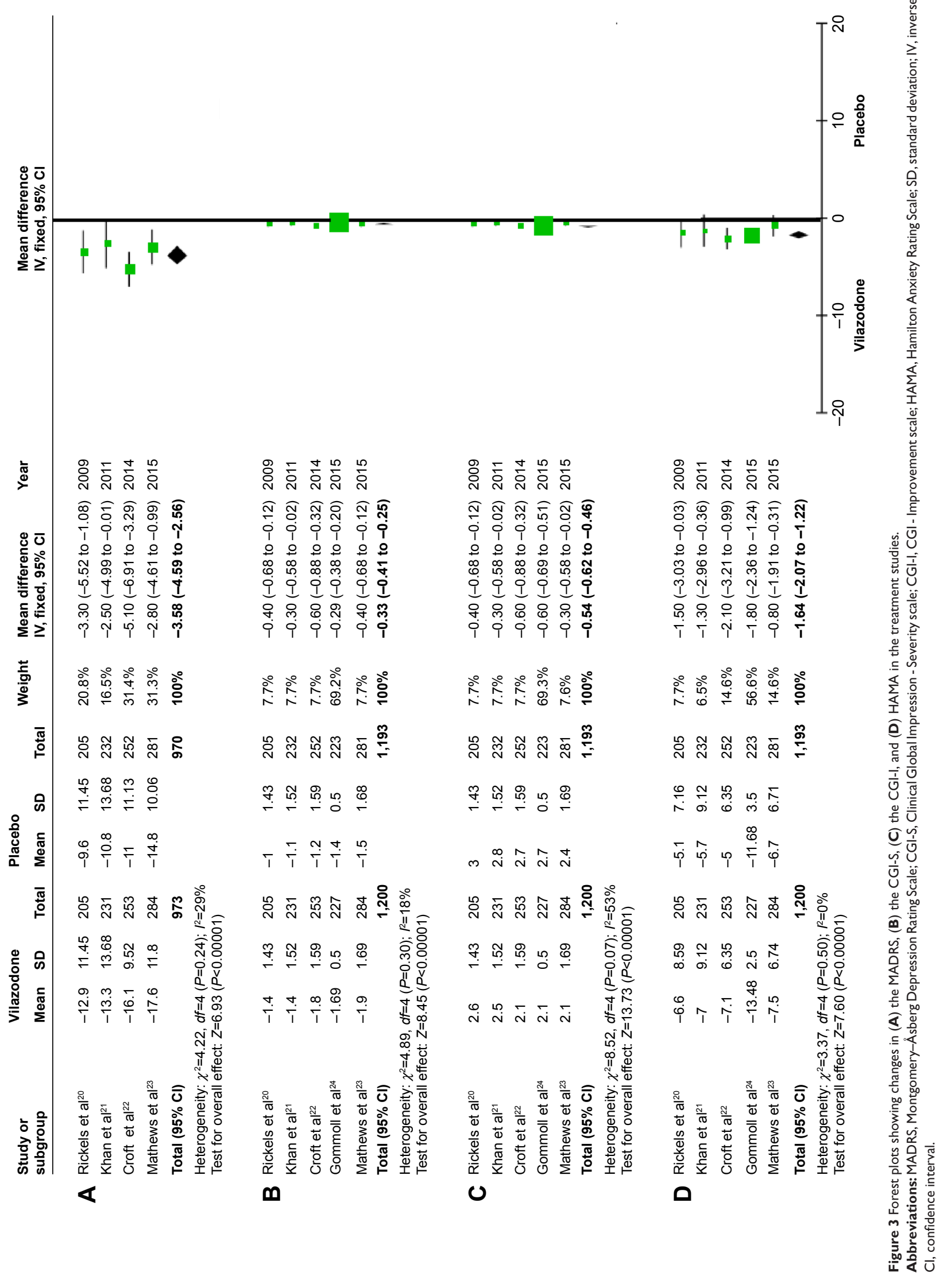




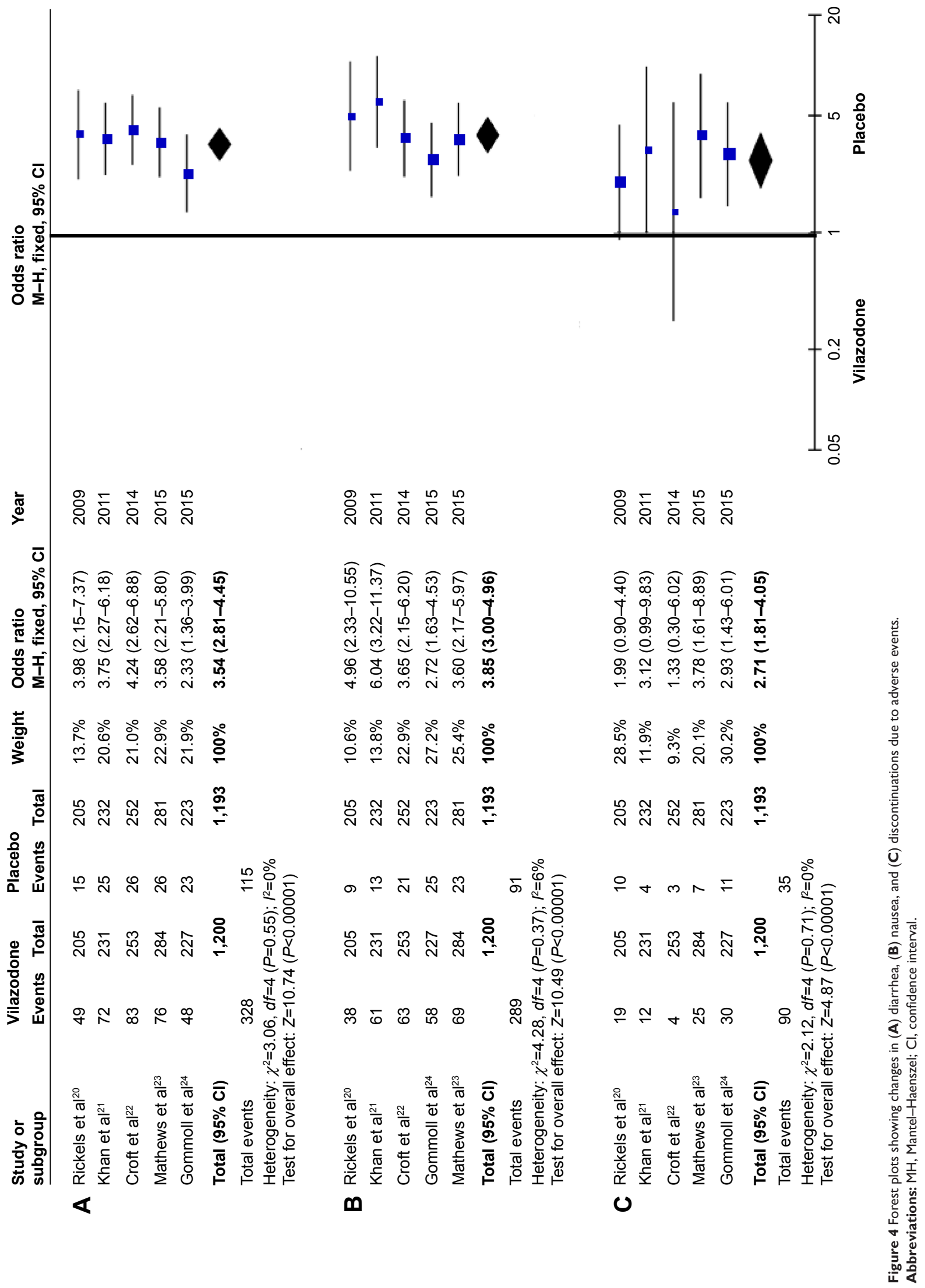


trials. According to the quality-assessment scale, we confirmed the quality of each study recruited in our analysis. Some limitations of the study should be mentioned. First, the number of included articles was small. Second, the articles did not research the safety and efficacy of vilazodone with longer-term use. Finally, we did not include unpublished studies. Bias may have occurred resulting from these limitations. Larger samples and more high-quality trials are needed to further investigate the efficacy and safety of vilazodone for patients with MDD.

\section{Conclusion}

Based on the meta-analysis, we provide further evidence that vilazodone is a safe and effective drug for patients with MDD. It offers promise as a novel oral drug for the treatment of MDD with its superior clinical efficacy and tolerability balance.

\section{Disclosure}

The authors report no conflicts of interest in this work.

\section{References}

1. Goodwin RD, Kroenke K, Hoven CW, Spitzer RL. Major depression, physical illness, and suicidal ideation in primary care. Psychosom Med. 2003;65(4):501-505.

2. Leon AC, Olfson M, Broadhead WE, et al. Prevalence of mental disorders in primary care. Implications for screening. Arch Fam Med. 1995;4(10):857-861.

3. Spitzer RL, Kroenke K, Linzer M, et al. Health-related quality of life in primary care patients with mental disorders: results from the PRIME-MD 1,000 study. JAMA. 1995;274(19):1511-1517.

4. Egede LE. Major depression in individuals with chronic medical disorders: prevalence, correlates and association with health resource utilization, lost productivity and functional disability. Gen Hosp Psychiatry. 2007;29(5):409-416.

5. Kessler RC, Berglund P, Demler O, et al. The epidemiology of major depressive disorder: results from the National Comorbidity Survey Replication (NCS-R). JAMA. 2003;289(23):3095-3105.

6. American Psychiatric Association. Diagnostic and Statistical Manual of Mental Disorders. 4th ed. Text revision. Washington: American Psychiatric Association; 2000.

7. Rush AJ, Trivedi MH, Wisniewski SR, et al. Bupropion-SR, sertraline, or venlafaxine-XR after failure of SSRIs for depression. N Engl J Med. 2006;354(12):1231-1242.

8. Rush AJ. STAR*D: what have we learned? Am J Psychiatry. 2007; 164(2):201-204.

9. Dawson LA, Watson JM. Vilazodone: a 5-HT1A receptor agonist/ serotonin transporter inhibitor for the treatment of affective disorders. CNS Neurosci Ther. 2009;15(2):107-117.

10. Hughes ZA, Starr KR, Langmead CJ, et al. Neurochemical evaluation of the novel 5-HT1A receptor partial agonist/serotonin reuptake inhibitor, vilazodone. Eur J Pharmacol. 2005;510(1-2):49-57.

11. Rickels K, Athanasiou M, Reed C. Vilazodone, a novel, dual-acting antidepressant: current status, future promise, and potential for individualized treatment of depression. Per Med. 2009;6(2):217-224.

12. Viibryd (vilazodone $\mathrm{HCl}$ ) [prescribing information]. New York, NY: Forest Laboratories Inc; 2013.
13. Viibryd (vilazodone) [prescribing information]. 2011. Available from: http://pi.actavis.com/data_stream.asp?product_ group $=1905 \& p=$ pi\&language $=E$. Accessed July 6, 2015.

14. Jain R, Chen D, Edwards J, Mathews M. Early and sustained improvement with vilazodone in adult patients with major depressive disorder: post hoc analyses of two phase III trials. Curr Med Res Opin. 2014; 30(2):263-270.

15. Khan A, Sambunaris A, Edwards J, Ruth A, Robinson DS. Vilazodone in the treatment of major depressive disorder: efficacy across symptoms and severity of depression. Int Clin Psychopharmacol. 2014; 29(2):86-92.

16. Jadad AR. Randomised Controlled Trials. London: BMJ Publishing Group; 1998.

17. Higgins JP, Green S, editors. Cochrane Handbook for Systematic Reviews of Interventions. Version 5.1.0. London: Cochrane Collaboration; 2011.

18. DerSimonian R, Laird N. Meta-analysis in clinical trials. Control Clin Trials. 1986;7(3):177-188.

19. Higgins JP, Thompson SG, Deeks JJ, Altman DG. Measuring inconsistency in meta-analyses. BMJ. 2003;327(7414):557-560.

20. Rickels K, Athanasiou M, Robinson DS, Gibertini M, Whalen H, Reed CR. Evidence for efficacy and tolerability of vilazodone in the treatment of major depressive disorder: a randomized, double-blind, placebo-controlled trial. J Clin Psychiatry. 2009;70(3):326-333.

21. Khan A, Cutler AJ, Kajdasz DK, et al. A randomized, double-blind, placebo-controlled, 8-week study of vilazodone, a serotonergic agent for the treatment of major depressive disorder. J Clin Psychiatry. 2011; 72(4):441-447.

22. Croft HA, Pomara N, Gommoll C, Chen D, Nunez R, Mathews M. Efficacy and safety of vilazodone in major depressive disorder: a randomized, double-blind, placebo-controlled trial. J Clin Psychiatry. 2014;75(11):e1291-e1298.

23. Mathews M, Gommoll C, Chen D, Nunez R, Khan A. Efficacy and safety of vilazodone 20 and $40 \mathrm{mg}$ in major depressive disorder: a randomized, double-blind, placebo-controlled trial. Int Clin Psychopharmacol. 2015;30(2):67-74.

24. Gommoll C, Durgam S, Mathews M, et al. A double-blind, randomized, placebo-controlled, fixed-dose phase III study of vilazodone in patients with generalized anxiety disorder. Depress Anxiety. 2015;32(6): $451-459$.

25. Penninx BW, Milaneschi Y, Lamers F, Vogelzangs N. Understanding the somatic consequences of depression: biological mechanisms and the role of depression symptom profile. BMC Med. 2013;11:129.

26. Marcus M, Yasamy MT, van Ommeren M, Chisholm D, Saxena S. Depression: A Global Public Health Concern. Geneva: World Health Organization; 2012.

27. Kessler RC, Chiu WT, Demler O, Merikangas KR, Walters EE. Prevalence, severity, and comorbidity of 12-month DSM-IV disorders in the National Comorbidity Survey Replication. Arch Gen Psychiatry. 2005; 62(6):617-627.

28. Centers for Disease Control and Prevention (CDC). Current depression among adults - United States, 2006 and 2008. MMWR Morb Mortal Wkly Rep. 2010;59(38):1229-1235.

29. McKnight PE, Kashdan TB. The importance of functional impairment to mental health outcomes: a case for reassessing our goals in depression treatment research. Clin Psychol Rev. 2009;29(3):243-259.

30. Kessler RC. The costs of depression. Psychiatr Clin North Am. 2012; 35(1):1-14.

31. American Psychiatric Association. Practice Guideline for the Treatment of Patients with Major Depressive Disorder. 3rd ed. Arlington (VA): American Psychiatric Association; 2010.

32. Hirschfeld RM, Keller MB, Panico S, et al. The National Depressive and Manic-Depressive Association consensus statement on the undertreatment of depression. JAMA. 1997;277(4):333-340.

33. Ferguson JM. SSRI antidepressant medications: adverse effects and tolerability. Prim Care Companion J Clin Psychiatry. 2001;3(1):22-27. 
34. Mark TL, Levit KR, Buck JA. Datapoints: psychotropic drug prescriptions by medical specialty. Psychiatr Serv. 2009;60(9):1167.

35. Wang SM, Han C, Lee SJ, Patkar AA, Masand PS, Pae CU. Vilazodone for the treatment of major depressive disorder: focusing on its clinical studies and mechanism of action. Psychiatry Investig. 2015;12(2): 155-163.

36. Wang SM, Han C, Lee SJ, Patkar AA, Masand PS, Pae CU. A review of current evidence for vilazodone in major depressive disorder. Int J Psychiatry Clin Pract. 2013;17(3):160-169.
37. Pierz KA, Thase ME. A review of vilazodone, serotonin, and major depressive disorder. Prim Care Companion CNS Disord. 2014;16(1).

38. Robinson DS, Kajdasz DK, Gallipoli S, Whalen H, Wamil A, Reed CR. A 1-year, open-label study assessing the safety and tolerability of vilazodone in patients with major depressive disorder. J Clin Psychopharmacol. 2011;31(5):643-646.

\section{Publish your work in this journal}

Neuropsychiatric Disease and Treatment is an international, peerreviewed journal of clinical therapeutics and pharmacology focusing on concise rapid reporting of clinical or pre-clinical studies on a range of neuropsychiatric and neurological disorders. This journal is indexed on PubMed Central, the 'PsycINFO' database and CAS, and is the official journal of The International Neuropsychiatric Association (INA). The manuscript management system is completely online and includes a very quick and fair peer-review system, which is all easy to use. Visit http://www.dovepress.com/testimonials.php to read real quotes from published authors.

Submit your manuscript here: http://www.dovepress.com/neuropsychiatric-disease-and-treatment-journal 